\title{
Adjustment and Scholastic Achievement among Higher Secondary Students of Residential and Non-Residential Schools
}

\author{
A.H.S. Vithal ${ }^{1} *$
}

\section{ABSTRACT}

The aim of this study was to find out the relationship of adjustment to scholastic achievement of Residential and Non Residential School students. The sample consisted of 30 Male students (Residential); 30 Female students (Residential); 30 Male students (Non Residential); 30 Female students (Non Residential) and their combined mean age was 16.27 years. The data was collected using tools: (1) Bell's Adjustment Inventory (Indian Adaptation) by Dr. Lalita Sharma. The statistical analysis was done by using mean, standard deviation, product moment correlation technique (r) and t-test. The findings are as follows: 1) There is significant positive relationship of adjustment to scholastic achievement $\left(0.768^{* *}\right)$. 2) There is no gender difference in the overall adjustment (0.185) and scholastic achievement (0.728). 3) There is no difference in the overall adjustment (0.772) and scholastic achievement (1.537) of residential and non-residential school students.

Keywords: Adjustment; Scholastic Achievement; Students; Schools

A child's attitude towards his own life, his family members and other objects is developed during his early life through his interactions within his own family followed by his contacts with peers. This is the early period of his social development which determines his adjustment in future with different people and situations. There is ample evidence to suggest that children brought up in liberal families are found in later life more successful in their adjustment in varied situations. On the other hand, children belonging to restrictive families are likely to be more dependent, obedient, non-creative, less dominant and comparatively more polite and submissive.

Dominant parents raise counter hostility in their child which may turn in future in his poor adjustment not only with his parents but also society at large. Not only his attitude for people but also for his scholastic career is affected by his early training of adjustment. It has been observed

\footnotetext{
${ }^{1}$ Assistant Professor, Department of Psychology, University College of Arts and Social Sciences, Osmania University, Hyderabad, Telangana, India

*Responding Author

(C) 2016 Vithal AH; licensee IJIP. This is an Open Access Research distributed under the terms of the Creative Commons Attribution License (http://creativecommons.org/licenses/by/2.0), which permits unrestricted use, distribution, and reproduction in any Medium, provided the original work is properly cited.
} 


\section{Adjustment and Scholastic Achievement among Higher Secondary Students of Residential and Non- Residential Schools}

by teachers that children, who have good working relationship with others, are found to score highly in their school examinations.

It has been found that the child who perceives himself to be able, confident, adequate and a person of worth has more energy to spend on academic achievement and will use his intelligence to be utmost on the other hand, the child who perceives himself as worthless, incapable and less confident may not come up to the optimum level of attainment.

The term 'adjustment' involves responses by which an individual strives to cope with his needs to bring harmony with his environment. Eysenck (1960) indicates that it is the state of mind of an individual in which his needs on the one hand and claims of his environment on the other hand are fully in harmony with each other. Social Adjustment refers to adaptation of an individual to the social environment. Adjustment may take place by adapting the self to the environment or by changing the environment. Emotional adjustment is the maintenance of emotional equilibrium in the face of internal and external stressors. This is facilitated by cognitive processes of acceptance and adaptation. An example would be maintaining emotional control and coping behaviour in the face of an identity crisis. This capacity is an important aspect of mental health and where it is compromised or not developed, psychopathology and mental disorder can result. The term 'scholastic achievement' has been explained by Good et al (1954) by the level of knowledge attained or skills developed in the schools subjects.

\section{REVIEW OF LITERATURE}

A study by Mohan Gupta and Renu Gupta (2010) examined the process of how some factors of adjustment leaves effect to children's scholastic achievement. These factors are emotional adjustment, social adjustment and educational adjustment.

The literature on adjustment consistently has clarified that factors of adjustment play an important role in children's scholastic achievement. The mechanisms for adjustment have not been well studied. This study aimed to know the level of adjustment and educational achievement of secondary school's children.

The tools, which are used in study are high reliable. Adjustment inventory of A.K.P. Sinha and Singh R.P. (1980) was used. Sample of 100 students was selected from various schools of Meerut. In which two groups were formed according to their gender. Statistics were used. Mean, S.D. \& Critical Ratio were calculated.

The finding shows that male students are showing significantly higher score than females, it means female children were better in social adjustment. While in educational adjustment the 


\section{Adjustment and Scholastic Achievement among Higher Secondary Students of Residential and Non- Residential Schools}

result shows that boys and girls have same order of adjustment. It means the opinion of teachers of co-educational institution that girls adjust better than boys is wrong.

This study is particularly important for opening the co-education institutions and for providing the additional education. Even though education is by no mean a quick intervention, it is more permanent and perhaps more impactable on the adjustmental environment.

\section{Studies on Gender and scholastic achievement}

Gender has been found to play an important role in influencing some personality variables and also children's scholastic activities. Some of the studies reported that gender has an adverse effect on the children's academic achievement.

Bridgeman and Wendler (1991) conducted a study on gender differences as predictors of college mathematics performance and in college mathematics course grades. The sample consisted of boys and girls enrolled in first year mathematics course from 9 universities. Grades and placement test scores of these boys and girls were obtained and combined with scholastic aptitude test scores and self-reported information on mathematics courses. Results showed that, boy's average scores on mathematical score of SAT were above the girls average scores but girls grades were slightly higher than the boy's average grades.

Vijaylaxmi and Natesan (1992) conducted a study on factors influencing academic achievement. The sample comprised of 100 students studying in XI standard of Coimbatore city. To assess socio-economic status of the subjects, Vendal's (1981) socio economic status scale was used. To assess academic achievement of the subjects, the total marks obtained in quarterly and half yearly examination was taken. Findings showed that girls had a higher mean academic achievement compared to boys. On an average, girls had greater achievement motivation than boys.

Lubinski and Benbow (1992) reviewed gender differences in mathematical reasoning as well as cognitive and non-cognitive attributes. Data was presented on abilities and values of students tested through the study of mathematically precocious youth at Iowa state university from 198891. Results revealed that males are tended to have more ability and preference profiles in mathematical reasoning than the females.

Kaur and Gill (1993) revealed that achievement in English and total achievement was independent of sex, but boys scored higher than girls in achievement in Punjabi, mathematics and science subjects. 


\section{Adjustment and Scholastic Achievement among Higher Secondary Students of Residential and Non- Residential Schools}

Ahmed (1998) conducted a study on achievement motivation differences among adolescent boys and girls of various ordinal birth positions. The study was conducted on a sample of 120 students belonging to age group of 13-18 years studying in coeducational English medium institutions confined to the suburbs of Mumbai city. Shafi's achievement motivation scale was used for data collection. Results revealed that the influence of sex on achievement motivation was statistically non-significant.

Fan and Chen (1997) conducted a study on gender differences in mathematics achievement. They investigated students from eighth, tenth and twelfth grades. Results showed that a small gender gap is observed among males and females in eighth grade and this gap expands in the tenth grade and also in the twelth grade in their mathematical achievement. They also found that male tend to have better visual and spatial abilities than that of females.

Joshi (2000) conducted a study on neuroticism, extraversion and academic achievement as related to gender and culture. The sample chosen for the study was 400 students of VIII class belonging to urban and rural area. Eysenck's personality inventory was used for data collection. Results revealed a significant difference between boys and girls of rural area on academic achievement, neuroticism and extraversion.

David Yun (2001) conducted a study to investigate gender differences in verbal and mathematics skills among Chinese adolescents. The study involved 208 tenth graders from a regular and a key school in China. The males at both schools scored higher than the females at the schools. Although males at the regular schools scored higher than the females at the schools when compared to key schools.

Suneetha and Mayuri (2001) conducted a study on age and gender differences on the factors affecting high academic achievement of school children. The total sample of the study comprised of 120 children of IX and X grade drawn purposively from 10 private schools of Hyderabad. Malin's intelligence scales for Indian children, study habit inventory, multidimensional assessment of personality inventory were used for data collection. The results showed no significant differences among boys and girls with respect to IQ dimensions. Boys and girls differed significantly in drilling, interaction, sets and language dimensions of study habits inventory and also in all the dimensions of MAP series except in self-control and tension.

Pomerantzet al. (2002) conducted study on making the grade but feeling distressed gender differences in academic performance of internal distress. The sample consisted of 932 elementary school children (466 girls, 466 boys) in two lower to middle-class school districts in the Midwest. For assessing academic performance, Children's grades in four subjects, language, social studies, science and maths were obtained. Internal distress was assessed with a measure 


\section{Adjustment and Scholastic Achievement among Higher Secondary Students of Residential and Non- Residential Schools}

designed by the researcher. Results reported that, girls out performed boys across all 4 subjects and were more prone to internal distress than boys.

Some studies have indicated that girls scholastic achievement was higher than the boys. And some studies reported boys scored higher than the girls in some subjects like mathematics reasoning, visual and spatial abilities.

\section{Statement Of The Problem}

- To compare adjustment and scholastic achievement among higher secondary students of Residential and Non-Residential Schools.

\section{Objectives}

1. To find out whether there is any difference in the level of adjustment among higher secondary students of Residential and Non-Residential schools.

2. To find out whether there is any gender difference in the level of adjustment among higher secondary students of Residential and Non-Residential schools.

3. To study whether there is any difference in the level of scholastic achievement among higher secondary students of Residential and Non-Residential schools.

4. To study find out whether there is any gender difference in the level of scholastic achievement among higher secondary students of Residential and Non-Residential schools.

5. To determine the relation between adjustment and scholastic achievement among higher secondary students of Residential and Non-Residential schools.

\section{Hypotheses}

1. There will not be any difference in the level of adjustment among Residential School students and non-residential school students.

2. There will not be any gender difference in the level of adjustment of students.

3. There will not be any difference in the level of scholastic achievement between residential and non-residential school students.

4. There will not be any gender difference in the level of scholastic achievement of students.

5. There will be a significant relationship between adjustment and scholastic achievement of students.

\section{Instrument}

Indian Adaptation of the Bell's Adjustment Inventory by Dr. Lalita Sharma, was used as an Instrument for this study. In this inventory, there are 80 statements which are to be answered in yes/no form. The 80 statements are classified into 4 areas of Adjustment: Family, Emotional, Social and Health. Scoring is done according to the instructions given in the manual. The

(c) The International Journal of Indian Psychology, ISSN 2348-5396 (e)| ISSN: 2349-3429 (p) | 116 
scholastic achievement score was arrived at by taking into consideration the percentage of marks obtained at their previous examination.

\section{Sample}

The sample consisted of 60 students of Residential School (30 boys \& 30 girls) and 60 students of Non-residential school (30 boys \& 30 girls). Their combined mean age was 16.27 years.

\section{Procedure}

After the permission is obtained to conduct the study, suitable time was fixed to conduct the test. After a rapport is established with the students, the Indian Adaptation of Bell's Adjustment Inventory was given along with the following instructions:

"I am going to present you with a booklet. Please give your basic information on the first page of the booklet. Now turn to page 2 of the booklet. You will see some statements with response options yes/no. You have to tick mark only one response either yes/no for each statement. These statements help me in understanding you better. There are no right or wrong responses. Mark your responses honestly. Your responses will be kept strictly confidential. You may approach me if there are any doubts. There is no time limit, but try to complete as soon as possible.”

\section{RESULTS AND DISCUSSION}

Table 1 showing mean, standard deviation and t-ratio valueson adjustment scale for residential and non-residential school students

\begin{tabular}{|c|c|c|c|c|c|c|c|}
\hline & $\begin{array}{l}\text { Type of } \\
\text { School }\end{array}$ & $\mathbf{N}$ & Mean & $\begin{array}{l}\text { Std. } \\
\text { Deviation }\end{array}$ & $t$ & df & $\begin{array}{l}\text { Sig. (2- } \\
\text { tailed) }\end{array}$ \\
\hline $\begin{array}{l}\text { Family } \\
\text { Adjustment }\end{array}$ & $\begin{array}{l}\text { Residential } \\
\text { Non } \\
\text { Residential }\end{array}$ & $\begin{array}{l}60 \\
60\end{array}$ & $\begin{array}{l}7.17 \\
5.92\end{array}$ & $\begin{array}{l}5.866 \\
5.527\end{array}$ & 1.201 & 118 & .232 \\
\hline $\begin{array}{l}\text { Social } \\
\text { Adjustment }\end{array}$ & $\begin{array}{l}\text { Residential } \\
\text { Non } \\
\text { Residential }\end{array}$ & $\begin{array}{l}60 \\
60\end{array}$ & $\begin{array}{l}8.45 \\
7.05\end{array}$ & $\begin{array}{l}6.198 \\
5.375\end{array}$ & 1.322 & 118 & .189 \\
\hline $\begin{array}{l}\text { Emotional } \\
\text { Adjustment }\end{array}$ & $\begin{array}{l}\text { Residential } \\
\text { Non } \\
\text { Residential }\end{array}$ & $\begin{array}{l}60 \\
60\end{array}$ & $\begin{array}{l}9.48 \\
9.93\end{array}$ & $\begin{array}{l}6.280 \\
6.431\end{array}$ & .388 & 118 & .699 \\
\hline $\begin{array}{l}\text { Health } \\
\text { Adjustment }\end{array}$ & $\begin{array}{l}\text { Residential } \\
\text { Non } \\
\text { Residential }\end{array}$ & $\begin{array}{l}60 \\
60\end{array}$ & $\begin{array}{l}7.08 \\
6.52\end{array}$ & $\begin{array}{l}5.762 \\
4.873\end{array}$ & .582 & 118 & .562 \\
\hline $\begin{array}{l}\text { Overall } \\
\text { Adjustment }\end{array}$ & $\begin{array}{l}\text { Residential } \\
\text { Non } \\
\text { Residential }\end{array}$ & $\begin{array}{l}60 \\
60\end{array}$ & $\begin{array}{l}32.18 \\
29.42\end{array}$ & $\begin{array}{l}20.981 \\
18.200\end{array}$ & .772 & 118 & .442 \\
\hline
\end{tabular}




\section{Adjustment and Scholastic Achievement among Higher Secondary Students of Residential and Non- Residential Schools}

\section{Family adjustment:}

The mean for residential group on the dimension family adjustment is $\mathbf{7 . 1 7}$ while the mean for non-residential group is $\mathbf{5 . 9 2}$. There is slight difference in the means, the residential group being slightly higher on the family adjustment.

The standard deviation for the residential and the non-residential groups is $\mathbf{5 . 8 6 6}$ and $\mathbf{5 . 5 2 7}$ respectively. The standard deviation is almost same for both the groups and both the groups have same variance.

There is no significant difference in the family adjustment of residential and non-residential groups ( $\mathbf{t = 1 . 2 0 1 )}$

\section{Social adjustment:}

The mean for the residential and the non-residential group is 8.45 and 7.05 respectively. Residential students seem to be better socially adjusted than the non-residential students.

Standard deviation for residential is $\mathbf{6 . 1 9 4}$ while for non-residential it is 5.375. The nonresidential group is slightly more homogeneous than the residential group.

There is no significant difference in the social adjustment of the residential and the nonresidential group. $(\mathrm{t}=\mathbf{1 . 3 2 2})$

\section{Emotional adjustment:}

The mean for the residential and the non-residential group is 9.48 and 9.93 respectively. There is very little difference in the means of both the groups which indicates that both are at par with one another.

For emotional adjustment the SD of residential and non-residential is 6.28 and 6.431 respectively. The variance in the scores of both the groups is almost same.

There is no significant difference in the emotional adjustment of the residential and the nonresidential groups. $\mathbf{( t = \mathbf { 0 . 3 8 8 } )}$

\section{Health adjustment:}

The mean for health adjustment for residential and non-residential is $\mathbf{7 . 0 8}$ and $\mathbf{6 . 5 2}$ respectively. There is not much of difference in the health adjustment of both the groups (residential and nonresidential).

The standard deviation for residential group is $\mathbf{5 . 7 6 2}$ while that for the non-residential group is 4.873. Residential group seem to have slightly more variance than the non-residential group.

There is no significant difference in the health adjustment of residential and non-residential groups. ( $\mathbf{t = 0 . 5 8 2 )}$ 
Adjustment and Scholastic Achievement among Higher Secondary Students of Residential and NonResidential Schools

Table 2 showing gender differences on dimensions of adjustment

\begin{tabular}{|l|l|l|l|l|l|l|l|}
\hline & Gender & $\mathbf{N}$ & Mean & $\begin{array}{l}\text { Std. } \\
\text { Deviation }\end{array}$ & t & df & $\begin{array}{l}\text { Sig. (2- } \\
\text { tailed) }\end{array}$ \\
\hline $\begin{array}{l}\text { Family } \\
\text { Adjustment }\end{array}$ & Female & 60 & 7.12 & 6.322 & 1.104 & 118 & .272 \\
\hline Macial & Female & 60 & 6.97 & 5.012 & & & \\
Adjustment & Male & 60 & 8.35 & 6.441 & 1.131 & 118 & .260 \\
\hline Emotional & Female & 60 & 8.15 & 5.108 & & & \\
Adjustment & Male & 60 & 11.05 & 6.098 & $\mathbf{2 . 3 6 5 *}$ & 118 & .020 \\
\hline Health & Female & 60 & 6.328 & & & \\
Adjustment & Male & 60 & 6.97 & 4.981 & .342 & 118 & .733 \\
\hline $\begin{array}{l}\text { Overall } \\
\text { Adjustment }\end{array}$ & Female & 60 & 30.47 & 20.706 & .185 & 118 & .853 \\
\hline
\end{tabular}

\section{Family Adjustment}

The mean of family adjustment for males is $\mathbf{5 . 9 7}$ while that for females is $\mathbf{7 . 1 2}$. Though there is not much of difference but the females are little higher on family adjustment.

Standard deviation for family adjustment for males and females $\mathbf{5 . 0 1 2}$ and $\mathbf{6 . 3 2 2}$ respectively. Female group is slightly more heterogeneous than the males.

There is no significant gender difference in the family adjustment. ( $(\mathbf{t = 1 . 1 0 1 4})$

\section{Social Adjustment}

The mean for social adjustment for males is $\mathbf{7 . 1 5}$ and for females is8.35. Again here females seem to be slightly more adjusted in the social sphere than males.

For social adjustment, SD for males is $\mathbf{5 . 1 0 8}$ and for females it is $\mathbf{6 . 4 4 1}$. This means that there is little more variance in the female group than the male group.

There is no significant gender difference in the social adjustment $(\mathbf{t}=\mathbf{1 . 1 3 1})$

\section{Emotional Adjustment}

The mean for emotional adjustment for males is $\mathbf{8 . 3 7}$ and for females it is 11.05. It is clearly evident that females have better emotional adjustment than males.

For males the standard deviation is $\mathbf{6 . 0 9 8}$ and for females it is $\mathbf{6 . 3 2 8}$. Both the groups have similar variance in their scores.

Significant difference in emotional adjustment for males and females $(\mathbf{t}=\mathbf{2 . 3 6 5 *})$

\section{Health Adjustment}

The mean for health adjustment for males and females is 6.97 and 6.63 respectively. Males have a slightly higher health adjustment than females.

(c) The International Journal of Indian Psychology, ISSN 2348-5396 (e)| ISSN: 2349-3429 (p) | 119 
The standard deviation for males is $\mathbf{5 . 6 7 8}$ and for females it is $\mathbf{4 . 9 8 1}$. Males seem to be more heterogeneous than females.

There is no significant difference in health adjustment for males and females $(\mathbf{t}=\mathbf{0 . 3 4 2})$

\section{Overall Adjustment}

The mean for overall adjustment for males is $\mathbf{3 1 . 1 3}$ while that for the females is $\mathbf{3 0 . 4 7}$. This means that overall, males are slightly better adjusted than females.

For males the Standard deviation for overall adjustment is $\mathbf{1 8 . 6 1 1}$ and that for females is 20.706. This means that there is greater homogeneity in the male group compared to females.

There is no significant gender difference in overall adjustment $\mathbf{( t = \mathbf { 0 . 1 8 5 } )}$

Table 3showing Mean, Standard Deviation and t-ratio values for Scholastic Achievement among Residential and Non-Residential School Students

\begin{tabular}{|l|l|l|l|l|l|l|l|}
\hline & $\begin{array}{l}\text { Type of } \\
\text { School }\end{array}$ & $\mathbf{N}$ & Mean & $\begin{array}{l}\text { Std. } \\
\text { Deviation }\end{array}$ & t & df & $\begin{array}{l}\text { Sig. (2- } \\
\text { tailed) }\end{array}$ \\
\hline $\begin{array}{l}\text { Scholastic } \\
\text { Achievement }\end{array}$ & $\begin{array}{l}\text { Residential } \\
\text { Non- } \\
\text { Residential }\end{array}$ & 60 & 69.15 & 14.700 & 1.539 & 118 & .127 \\
\hline
\end{tabular}

The mean for the residential group is $\mathbf{6 9 . 1 5}$ and non-residential group is $\mathbf{7 3 . 3 0}$. The nonresidential school students have a slightly higher scholastic achievement than the residential group. The standard deviation value for scholastic achievement for residential school students is 14.700 and the non-residential school students is14.848. Both the groups have almost same variance. The t-ratio value on scholastic achievement of residential and non-residential school students is $\mathbf{1 . 5 3 9}$ which indicates that there is no significant difference between the two groups.

Thus the hypothesis there will not be any difference in the level of scholastic achievement between residential and non-residential school students is accepted.

Table 4 showing t ratio values for Scholastic achievement among boys and girls

\begin{tabular}{|l|l|l|l|l|l|l|l|}
\hline & $\begin{array}{l}\text { Gender } \\
\text { of the } \\
\text { Subject }\end{array}$ & $\mathbf{N}$ & Mean & $\begin{array}{l}\text { Std. } \\
\text { Deviation }\end{array}$ & t & df & $\begin{array}{l}\text { Sig. (2- } \\
\text { tailed) }\end{array}$ \\
\hline $\begin{array}{l}\text { Scholastic } \\
\text { Achievement }\end{array}$ & $\begin{array}{l}\text { Male } \\
\text { Female }\end{array}$ & 60 & 72.22 & 13.748 & .730 & 118 & .467 \\
\hline
\end{tabular}

The mean for scholastic achievement for males is $\mathbf{7 2 . 2 2}$ and for females it is 70.23. Males have slightly higher Scholastic achievement than females. The standard deviation value for males is

(c) The International Journal of Indian Psychology, ISSN 2348-5396 (e)| ISSN: 2349-3429 (p) | 120 
13.748 and for females the SD is 15.946. The female group has a higher variance than the male group in scholastic achievement. However, the t-ratio is $\mathbf{0 . 7 3 0}$ which indicates no significant gender difference in scholastic achievement. Thus, the hypothesis which states that there will not be any gender difference in the level of scholastic achievement of students is accepted.

Table 5 showing the relationship between adjustment and scholastic achievement Correlation

\begin{tabular}{|l|l|l|l|}
\hline & & $\begin{array}{l}\text { Scholastic } \\
\text { Achievement \% }\end{array}$ & Overall Adjustment \\
\hline & Pearson Correlation & 1 & $.768^{* *}$ \\
\hline $\begin{array}{l}\text { Scholastic } \\
\text { Achievement \% }\end{array}$ & Sig. (2-tailed) & & .000 \\
\hline & $\mathrm{N}$ & 120 & 120 \\
\hline & Pearson Correlation &. $\mathbf{7 6 8} * *$ & 1 \\
\hline Overall Adjustment & Sig. (2-tailed) & .000 & 120 \\
\hline & N & 120 & \\
\hline
\end{tabular}

**. Correlation is significant at the 0.01 level (2-tailed).

From the correlation table it can be seen that there is a high correlation of adjustment to scholastic achievement (0.768**). This means that if an individual is high on adjustment, he/she is more likely to score high on scholastic achievement. So if an individual wants to fare well in academics, he/she should first try to improve his/her adjustment on various spheres of life.

\section{Acknowledgments}

The author appreciates all those who participated in the study and helped to facilitate the research process.

\section{Conflict of Interests}

The author declared no conflict of interests.

\section{REFERENCES}

Ahmed, J. (1998). Achievement Motivation Differences among Adolescent Boys and Girls of Various Ordinal Birth Position. Indian Psychological Review, 50(1), 2-5.

Bridgeman,\& B. (1991). Gender differences in predictors of college mathematics performance and grades in college mathematics courses. Journal of Educational Psychology,83, 275284.

Fan, X., \& Chen, M. (1997). Gender differences in mathematics achievement: Findings from the National Education Longitudinal Study of 1988. Journal of Experimental Education, 63(3), 229-242.

(C) The International Journal of Indian Psychology, ISSN 2348-5396 (e) I ISSN: 2349-3429 (p) | 121 
Joshi, G., 2000, Neuroticism, extraversion and academic achievement as related to gender and culture. Indian Psy. Rev., 54(1-2): 74-78.

Lubinski, D., Benbow, \& P., C. (1992). Gender differences in abilities and preferences among the gifted: Implications for the math/science pipeline. Current Directions in Psychological Science, 1, 61-66.

Mohan and Renu Gupta, Adjustment and Scholastic Achievement of Boys \& Girls. VSRDIJBMR, Vol. 1 (1), 2011, 29-33.

Pomerantz, E.M., Saxon, J.L. and Altermatt, E.R., 2002, Making the grade but feeling distresses: gender differences in academic performance in internal distress. J.Edu. Psy. 94(2): 396-404.

Suneetha, B. and Mayuri, K., 2001, A study on age and gender differences on the factors affecting high academic achievement. J. Comm. Guid. Res., 18(2): 197-208.

Vijayalaxmi, N. and Natesan, H., 1992, Factors influencing academic achievement. Res.High,2:62.

How to cite this article: Vithal AH (2016), Adjustment and Scholastic Achievement among Higher Secondary Students of Residential and Non-Residential Schools, International Journal of Indian Psychology, Volume 4, Issue 1, No. 82, ISSN:2348-5396 (e), ISSN:2349-3429 (p), DIP:18.01.152/20160401, ISBN:978-1-365-59365-9 